\title{
Relationship between soil aggregate strength, shape and porosity for soils under different long-term management
}

\author{
L.J. Munkholm, R.J. Heck, B. Deen, and T. Zidar
}

This is a post-peer review, pre-copyedit version of an article published in Geoderma. The final authenticated version is available online at: https://doi.org/10.1016/j.geoderma.2016.01.005.

Suggested Citation: Munkholm, L.J., Heck, R.J., Deen, B., \& Zidar, T. Relationship between soil aggregate strength, shape and porosity for soils under different long-term management. Geoderma 268, 52-59 (2016).

https://doi.org/10.1016/j.geoderma.2016.01.005

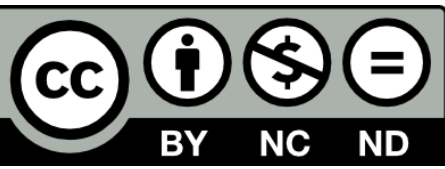


1 Relationship between soil aggregate strength, shape and porosity for soils under different long2 term management

4 Lars J. Munkholm*1, Richard J. Heck ${ }^{2}$, Bill Deen ${ }^{3}$, Zidar, T. ${ }^{2}$

$5 \quad{ }^{1 *}$ Aarhus University, Department of Agroecology, PO Box 50, DK-8830, Tjele, Denmark. E-mail:

6 lars.munkholm@agro.au. Phone no. +45 87157727.

7 2University of Guelph, School of Environmental Sciences, Guelph, ON, N1G 2W1 Canada.

$8 \quad{ }^{3}$ University of Guelph, Department of Plant Agriculture, Guelph, ON, N1G 2W1 Canada.

$9 *$ Corresponding author

10 Number of Tables: 3

11 Number of Figures: 5

12 Submitted to Geoderma, September $2^{\text {nd }} 2015$

13

14 Keywords: aggregates, tillage, crop rotation, $X$-ray CT, tensile strength, shape, porosity 
17 Soil aggregate properties, such as strength, shape and porosity, influence a range of essential soil

18 functions and there is a need for more detailed understanding of the effect of soil management on 19 these aggregate properties. There is also a need for improved knowledge on the link between aggregate and bulk soil properties. The objective of this study was to quantify the long-term effect of rotation and tillage on aggregate shape, strength and pore characteristics, to evaluate the influence of aggregate shape and pore characteristics on aggregate strength and soil friability and to correlate aggregate properties to bulk soil properties. Soil core samples were taken in spring 2010 from the long-term rotation and tillage trial (initiated in 1980) at the University of Guelph, Canada. The rotations included were continuous corn (R1) and a diverse rotation (R6), and the tillage treatments were mouldboard ploughing (MP) and no-tillage (NT). The soil cores were exposed to a drop shatter test and air-dried before separation into different size fractions. Ten aggregates from the 4-9.2 mm size fraction per core sample (i.e. 320 in all) were X-ray micro-CT scanned. The size, shape and porosity of the aggregates were determined using image analysis with $40 \mu \mathrm{m}$ voxel size. Subsequently, aggregate tensile strength was determined in an indirect tension test. Rotation had a more pronounced effect than tillage treatment on the different aggregate properties. The diverse rotation resulted in higher aggregate total porosity and more rounded aggregates than the continuous corn rotation. Surprisingly, there was no treatment effect on X-ray micro-CT resolvable porosities. Aggregate strength decreased with both total and X-ray micro-CT resolvable porosity even though the correlations were weak. Significant correlation was also found to aggregate sphericity although only around $10 \%$ of the variation in tensile strength could be explained by this property. Our study highlights that caution must be taken when trying to predict aggregate strength from general aggregate characteristics. For both bulk soil and aggregates, the R6-MP had highest and R1-NT lowest porosity. Tillage had strongest effect on bulk soil porosity, whereas aggregate total porosity was only affected by rotation. Our results suggest that the scale of observation is important when evaluating the influence of soil management. A strong correlation was found between aggregate strength and pore characteristics and soil fragmentation in a drop shatter test, i.e. $55 \%$ of the variation could be explained. Our study indicates therefore that bulk soil fragmentation behavior can be predicted from aggregate characteristics. It needs to be highlighted that our results are based on one long-term experiment on a silt loam soil. The results need to be verified for soils with different soil types, climates and management histories. 
Soil aggregate properties influence a range of essential soil functions such as erodibility (Kay and Dexter 1990), seedbed quality (Braunack et al., 1989; Håkansson et al., 2002) and greenhouse gas emissions (Ball, 2013). Despite the apparent key role of aggregates in soil, they are not easy objects to study. First of all they are often not very distinct and may be organized in complex hierarchical structures. As Young et al. (2001) pointed out "the existence of aggregates is probably a consequence of how we choose to observe them". Kay and Angers (2001) also reflected on the concept of aggregates; they defined the term aggregate as a structural unit resulting from fragmentation of bulk soil, induced by application of mechanical energy. This definition will also be applied in this paper. Young et al. (2001) also questioned the use of aggregates as a surrogate of soil structure per se as the observation of aggregates, extracted from the whole, only provides limited spatial information. Munkholm (2011) expressed a similar concern in the study of soil friability and called for studies exploring the correlations between observations at different scale.

The importance of aggregate structure to soil function has stimulated extensive research on the effect of soil type, climate and soil management on aggregate characteristics at different scales of observation. At the field level, there is a strong focus on qualitative assessment of size, shape and strength of aggregates in relation to soil profile classification (FAO, 1990) as well as on soil structural quality (Ball et al., 2007; 2015). Qualitative field assessments, have in many cases been supplemented with or exchanged by more detailed observations on aggregate size and shape (Dexter, 1985), strength (Braunack et al., 1979) and stability (e.g. Le Bissonnais, 1996). Dexter (1985) and Holden (1993) presented methods to quantify the shape on 2D projected images. They focussed on quantification of aspect ratio, sphericity and roundness based on 2D projected images and references also was drawn to the standard charts to describe particle morphology (Krumbein and Sloss, 1963).

Roundness has been found, in a study on Australian and Dutch soils (Dexter, 1985), to decrease with increasing clay and decreasing organic matter content. A study on a silt loam soil from Kentucky showed that zero-tillage resulted in significantly more elongated aggregates than mouldboard ploughing (Perfect et al. 1997). Holden (1995) indicated that aggregates from an old pasture varied from year to year, in relation to surface roughness, but not in relation to roundness. More studies are 
The vital importance of soil pore characteristics, for soil strength and fragmentation, has been shown in many cases (e.g. Munkholm et al., 2002a,b; Hallett et al., 1995). New advances in X-ray CT imagery have allowed visualization and quantification of the 3D structure of macropores within and between aggregates (e.g. Peth et al., 2008). A few studies have utilized this technique, to study the relationship between pore characteristics and aggregate tensile strength and soil fragmentation Munkholm et al., 2012; Naveed et al., 2014). They confirm the major influence of pore space on strength and fragmentation. Surprisingly, there is a paucity of studies on the influence of aggregate shape on strength despite being recognized, for decades (Dexter and Kroesbergen, 1985), as major source of variation. Recently, Seben et al. (2013) found a clear influence of aggregate shape on aggregate strength and variation in strength, i.e. aggregates with flat surfaces were weaker and showed smaller variability. Novel X-ray CT imagery has opened up for 3D quantification of aggregate shape. Garbout et al. (2013) quantified the 3D shape of aggregate clusters in terms of thickness, sphericity and roundness, but they did not relate the shape properties to strength. More studies are clearly needed to evaluate and quantify the effect of shape and also the combined effect of shape and pore characteristics.

This paper will focus on the relationship between aggregate strength, shape and porosity for soils under different long-term soil management. The issue of scale will also be considered as links will be drawn to bulk soil porosity and fragmentation measured on minimal disturbed soil cores taken from the same treatments in the field (Munkholm et al., 2012; 2013).

The objectives of this study were: 1. To quantify the long-term effect of rotation and tillage on aggregate shape, strength and pore characteristics, 2 . To evaluate the influence of aggregate shape and pore characteristics on aggregate strength and soil friability. 3. To correlate aggregate properties to bulk soil properties. Our hypotheses were: A. Rotation and tillage have a significant on aggregate strength, shape and pore characteristics, B. Aggregate strength decreases with porosity and variation in strength increases with irregularity, C. Aggregates resemble bulk soil pore and strength characteristics.

2. Materials and methods

\subsection{The experiment}


Samples were taken from the long-term rotation and tillage trial (initiated in 1980) at the University

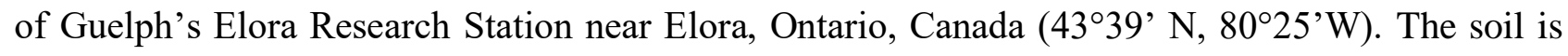
mapped as Woolwich silt loam and classified as a Grey Brown Luvisol (CSSC, 1998) or Albic

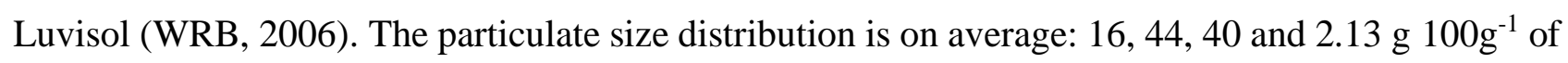
clay, silt, sand and organic carbon, respectively. The 30-year average rainfall (1970-2000) was 920 $\mathrm{mm}$, and the average monthly temperatures for January, April and July are -7.6, 5.9 and $19.7^{\circ} \mathrm{C}$, respectively.

The experimental design is a randomized split plot with four replicates. The main plot treatment is rotation and the split plot treatment is tillage. Seven four-course rotations are included in the trial. In this study we used rotation R1,(C-C-C-C) continuous corn (Zea mays L.) and rotation R6, (C-C$\mathrm{O}(\mathrm{RC}), \mathrm{B}(\mathrm{RC})$ ) corn, corn, oats (Avena fatua L.), spring barley (Hordeum vulgare L.) with a red clover (Trifolium pratense L.) cover crop underseeded in both oats and spring barley. The red clover cover crop was terminated using glyphosate late October, 2009. In 2010, first year corn was grown in R6. The tillage treatments included no tillage (NT) and conventional tillage with mouldboard ploughing (MP). Mouldboard ploughing $(20 \mathrm{~cm})$ was carried out on November 18 2009. Secondary tillage in MP consisted of two passes of a field cultivator $(10 \mathrm{~cm})$ and packer within 1 day of crop seeding. The tillage plots are $6 \times 16.5 \mathrm{~m}$ and 8 rows of corn were sown in each of the studied plots on May 7 2010. The corn crop was harvested at full maturity on October 19 and the yield was recorded.

\subsection{Soil core sampling}

Two minimally disturbed soil cores $(\varnothing=6.4 \mathrm{~cm}$, height $=8.0 \mathrm{~cm})$ were taken per at $10-20 \mathrm{~cm}$ depth in R1 and R6 on May 28 2010. In all, 32 samples were taken (i.e. 8 samples for each of the rotation $\mathrm{x}$ tillage treatments). The sampling depth was chosen to obtain soil affected by the tillage systems but minimally affected by within season root growth. The samples were taken in the centre of the plots in between rows, which had not been trafficked at the time of seeding (Munkholm et al., 2012). The crop was at corn at 6 leaf tip stage at sampling and therefore few roots were observed in the cores. The intact field moist samples were subjected to a drop shatter test after X-ray micro-CT scanning, as outlined by Munkholm et al. (2013). From the drop shatter test we obtained four oven-dry aggregate size fractions 0-1, 1-2, 2-4, 4-9.2 and 9.2-19 $\mathrm{mm}$ and used the 4-9.2 $\mathrm{mm}$ size fraction in this study. For the 4-9.2 mm size fraction ten aggregates were randomly selected for each of the 32 samples and gently transferred to a PVC cylinder $(\varnothing=6.4 \mathrm{~cm})$ where they were laid one by one in one side of the cylinder as shown in Figure 1. Ten aggregates from another sample were laid one by one 
in the other side of the cylinder. Two pieces of cardboard were used to separate the aggregates into four compartments with 5 aggregates in each. The cylinder was photographed (Figure 1) and this picture was used to label and identify the single aggregates. Thereafter, a piece of cardboard was laid on top of the first layer and new layer of aggregates were installed. All in all two layers of 20 aggregates were installed in each cylinder, i.e. aggregates from 4 samples in each cylinder.

\subsection{CT scanning, binary thresholding and image analysis}

The cylinders with aggregates were scanned using an EVS (now GE Medical, London, Canada) micro-CT scanner, model MS8X-130. The samples were scanned at $120 \mathrm{kV}, 170 \mathrm{~mA}$ and with a 3500 millisecond integration time, generating an axial sequence of X-ray attenuation imagery with $40 \mu \mathrm{m}$ voxel size. The final reconstructed image had also a voxel size of $40 \mu \mathrm{m}$.

Please consult Munkholm et al. (2012) for more details on the scanning procedure and image reconstruction. The open source software programme ImageJ was used for binary thresholding and image analysis (Rasband, 2005). Binary imaging was carried out using the standardized and automated thresholding procedure developed by Elliott and Heck (2007) and as detailed by Munkholm et al. (2012). In the case of high attenuation in cardboard shelving that could not be separated by the method described above a special procedure was applied. The original image sequence was thresholded manually to isolate voxels higher than air but lower than true solid (i.e. aggregates). These values were set to zero; all else $=1$. This image was then multiplied (Image Calculator) by the original segmented image. In some cases, aggregates were barely touching each other within the scanned cylinders. If so a local area was chosen, using freehand selection, to ensure the least amount of distortion to the volume and ellipsoid measurements. The Erode plug-in was employed to separate the single aggregates.

160 For each cylinder scan, eight regions of interest (ROI) were created containing one compartment -

161 e.g. \#11B in Figure 1. That is each ROI contained 5 aggregates. For analysing the individual 162 aggregates the 3D Particle Analyzer plug-in in ImageJ (Doube et al, 2010) was used. The following 163 settings were chosen: Exclude on sides, Thickness, Surface area, Enclosed volume, Ellipsoids, Min 164 Volume=500000, Max Volume=infinity, Show particle stack. The latter was chosen to be able to 165 correlate individual aggregates with the photographic images showing the numbered aggregates 166 e.g. Figure 1. An example of 2D images of segmented \#11B aggregates is shown in Figure 2a. For 
determining aggregate volume (i.e. enclosed pore space as well as solid) we first applied the Binary operation "Fill Holes" on segmented images (Figure 2b), and then again we used the Particle Analyser operation with the above mentioned settings. Thereby we were able to obtain information on the entire volume of the aggregates including surface connected pore space. This procedure also resulted in a markedly reduced surface area as the surface area for surface connected pore space was excluded for the "filled holes" images.

\subsection{Porosity parameters}

174

The total porosity of the aggregates was estimated from:

91 of $2.65 \mathrm{~g} / \mathrm{cm}^{3}$ was assumed. 
193 Based on the image analysis a range of shape characteristics were estimated. The shortest $\left(l_{1}\right)$,

194 intermediate $\left(l_{2}\right)$ and longest $\left(l_{3}\right)$ length of the single aggregates were used to calculate the ratio's $1_{1} / l_{3}$ 195 and $1_{2} / l_{3}$. The equivalent cubic length $\left(L_{c}\right)$ was proposed by Perfect et al. (1997) as an appropriate 196 shape parameter given that aggregate aspect ratios in most cases are much closer to those for a cube 197 than for a sphere.

198

$L_{c}=\left[l_{1}\left(l_{2} / \sqrt{2}\right)\left(l_{3} / \sqrt{3}\right)\right]^{1 / 3}$

Eq. 5

199 The sphericity, Ss, of the aggregates was estimated from (Wadell, 1935):

$200 \quad S_{S}=\left[\pi^{\left.\frac{1}{3}\left(6 V_{T}^{f}\right)^{\frac{2}{3}}\right] /} A_{T}^{f}\right.$

Eq. 6

201 Where $A_{T}^{f}$ is the aggregated surface area determined from the "filled holes" images.

202 Supplementary to $S_{s}$ the sphericity of ellipsoidal objects, $S_{e}$ was as determined according to Sneed 203 and Folk (1958):

$204 S_{E}=\sqrt[3]{l_{1}^{2} / l_{2} l_{3}}$

Eq.7

\subsection{Tensile strength measurements}

Tensile strength of the scanned air-dry aggregates was measured following the procedure 207 described by Dexter and Kroesbergen (1985), which involved crushing the aggregates individually 208 between two parallel plates in an indirect tension test. The aggregate tensile strength (Y) was calculated from the equation (Dexter and Kroesbergen, 1985):

$$
Y=0.576 \times\left(F / d^{2}\right)
$$

Eq.8

211 where $F(\mathrm{~N})$ is the polar force required to fracture the aggregate and $\mathrm{d}(\mathrm{m})$ is the mean 212 aggregate diameter. In this study $d[\mathrm{~m}]$ was estimated from:

$$
d=d_{0}\left(\mathrm{~m} / \mathrm{m}_{\mathrm{x}}\right)^{1 / 3}
$$


where $d_{0}[\mathrm{~m}]$ is the mean aggregate diameter (6.6 $\mathrm{mm}$ for the tested $4-9.2 \mathrm{~mm}$ size-class), $m$

$215[\mathrm{~kg}]$ is the mass of the individual aggregate and $m_{x}[\mathrm{~kg}]$ is the mean mass of the 10 aggregates per 216 plot.

217 Friability index, FI, for the single size soil aggregate from each subplot was estimated from the 218 variation of the tensile strength data in relation to its mean (Watts and Dexter, 1998).

$219 F I=\sigma^{\sigma} / \bar{Y}$

where $\sigma_{y}$ and $\bar{Y}$ are the standard deviation and mean, respectively, of soil tensile strength from each experimental plot. Friability was classified according to Imhoff et al. (2002). F $<0.1$ not friable, 0.10.2 slightly friable, $0.2-0.5$ friable, $0.5-0.8$ very friable and $>0.8$ mechanically unstable.

\subsection{Statistical analysis}

All statistical analyses were carried out using SAS (Version 9.2, SAS Institute, Cary, NC) (SAS, 2005). We used PROC INSIGHT to test data for normality. The pore characteristics derived from X-ray CT imagery and the tensile strength data were log-transformed to yield normality. All other data were best fitted by a normal distribution. Averages were calculated for each plot and used in the calculation of mean and standard error. The averages were used as input in general linear models for test of treatment effects. For this purpose we used PROC MIXED in SAS. For the aggregates four outliers with very high or very low bulk density (BD) were deleted from the analysis, i.e. $\mathrm{n}=316$. A significance level of $\mathrm{P}<0.05$ was generally applied in this study.

Results

\subsection{Aggregate pore characteristics}

Rotation and tillage significantly affected some of the soil pore characteristics, whereas the interaction between rotation and tillage was not significant in any case. The core data showed significantly higher dry bulk density for NT $\left(1.46 \mathrm{~g} \mathrm{~cm}^{-3}\right)$ compared with MP $\left(1.28 \mathrm{~g} \mathrm{~cm}^{-3}\right)$ (Table 1, Munkholm et al. 2013). There was an insignificant $(\mathrm{P}=0.18)$ trend to higher $\mathrm{BD}$ for $\mathrm{R} 1$ than for R6. For the aggregates a R1 tended to have higher bulk density $(\mathrm{P}=0.09)$ than R6 (i.e. 1.69 and 1.65 $\mathrm{g} \mathrm{cm}^{-3}$ for R1 and R6, respectively). There was no significant effect of tillage $(\mathrm{P}=0.14)$. The bulk density increased from $1.37 \mathrm{~g} \mathrm{~cm}^{-3}$ for the soil cores to $1.67 \mathrm{~g} \mathrm{~cm}^{-3}$ for the aggregates corresponding to a decrease in total porosity from $49 \mathrm{~m}^{3} 100 \mathrm{~m}^{-3}$ to $37 \mathrm{~m}^{3} 100 \mathrm{~m}^{-3}$. No significant treatment effect 
was found on the X-ray micro-CT resolvable porosities. The pore volume detected $\left(\varepsilon_{\mathrm{T}}{ }^{\mathrm{CT}}\right)$ was on

244 average $9.6 \mathrm{~m}^{3} 100 \mathrm{~m}^{-3}$, which was approximately $25 \%$ of the total pore volume for the aggregates.

245 Most of the X-ray micro-CT resolvable pore space was connected to the surface of the aggregates, 246 i.e. $\varepsilon_{\mathrm{S}}^{\mathrm{CT}}$ was in average $7.9 \mathrm{~m}^{3} 100 \mathrm{~m}^{-3}$. On average, $1.8 \mathrm{~m}^{3} 100 \mathrm{~m}^{-3}$ of the $\mathrm{CT}$ resolvable porosity 247 were enclosed within the aggregates $\left(\varepsilon_{I}^{\mathrm{CT}}\right)$, which corresponded to $19 \%$ of the CT resolvable 248 porosity.

\subsubsection{Aggregate shape and strength characteristics}

For the aggregate shape characteristics, there was significant effect of rotation in some cases and of tillage in one case. The interaction between rotation and tillage was not significant for any of the parameters. Aggregates from the continuous corn rotation (R1) tended to havesignificantly $(\mathrm{P}=0.07)$ longest major length $\left(l_{3}\right)$, significantly lowest aspect ratios $(\mathrm{P}<0.05)\left(1_{1} / l_{3}\right.$ and $\left.1_{2} / l_{3}\right)$ and displayed lowest sphericity of ellipsoid objects $\left(\mathrm{S}_{\mathrm{E}}\right)(\mathrm{P}=0.08)$ (Table 2). The major lengths were $12.1 \mathrm{~mm}$ and $11.1 \mathrm{~mm}$ for R1 and R6, respectively. The $1_{1} / 1_{3}$ aspect ratios were 0.39 and 0.43 , for R 1 and R6 respectively and the $1_{2} / l_{3}$ aspect ratios were 0.65 and 0.69 respectively for $\mathrm{R} 1$ and $\mathrm{R} 6$. A tendency to higher $(\mathrm{P}=0.07)$ sphericity for spheres $\left(\mathrm{S}_{\mathrm{S}}\right)$ was observed for NT $(0.51)$ than for MP $(0.49)$. There was no significant effect of treatment on aggregate strength and friability. The friability indices could for all treatments be considered as "friable" according to the Imhoff et al. (2002) classification.

Across all treatments, aggregate tensile strength ( $\log \mathrm{Y})$ decreased significantly with total porosity, $\varepsilon_{\mathrm{T}}^{\mathrm{agg}}, \mathrm{X}$-ray CT resolvable porosity, $\varepsilon_{\mathrm{T}}{ }^{\mathrm{CT}}$ and with X-ray CT resolvable surface connected porosity, $\varepsilon_{S}{ }^{\mathrm{CT}}$ (Table 3). The correlations were weak $(\mathrm{r}<-0.18)$. There was no overall significant correlation between tensile strength and X-ray CT resolvable isolated pore volume $\varepsilon_{\mathrm{I}}{ }^{\mathrm{CT}}$. For the individual treatments, there was only significant correlation between strength and pore characteristics for the R1-NT treatment. In that case, there was relatively strong negative correlation to $\varepsilon_{\mathrm{T}}{ }^{\mathrm{CT}}(\mathrm{r}=-0.41)$ and $\varepsilon_{S}{ }^{\mathrm{CT}}(\mathrm{r}=-0.42)$ and weaker correlation to $\varepsilon_{\mathrm{I}}{ }^{\mathrm{CT}}(\mathrm{r}=-0.22)$. The correlation between $\log \mathrm{Y}$ and the pore characteristics $\varepsilon_{\mathrm{T}}^{\text {agg }}, \varepsilon_{\mathrm{T}}{ }^{\mathrm{CT}}$ and $\varepsilon_{\mathrm{S}}{ }^{\mathrm{CT}}$ is shown in Figure 3. 
Across all treatments there was a significant negative correlation between $\log \mathrm{Y}$ and $\log$ values of intermediate $\left(l_{2}\right)$, major $\left(l_{3}\right)$ and the equivalent cubic length $\left(L_{c}\right)$ (Table 3$)$. The correlations were weak, i.e. $r$ varied between -0.12 and -0.15 . On the other hand, $\log \mathrm{Y}$ increased significantly with the aspect ratio, $1_{2} / 1_{3}$, and with sphericity $\left(S_{S}\right.$ and $\left.S_{E}\right)$. Strongest correlation was found between $\log$ $\mathrm{Y}$ and $\mathrm{S}_{\mathrm{s}}(\mathrm{r}=0.31)$ corresponding to $\mathrm{R}^{2}=10$. This correlation was significant for all combinations of rotation and tillage. The correlation between $\log \mathrm{Y}$, and $\mathrm{l}_{2} / \mathrm{l}_{3}$ and $\mathrm{S}_{\mathrm{E}}$ were for the individual treatments only significant for R1-MP and R1-NT. Figure 4 shows correlations between $\log \mathrm{Y}$ and the shape characteristics $\log 1_{3}, 1_{2} / l_{3}$ and $S_{s}$.

\subsection{Correlation between drop shatter results and strength and pore characteristics}

The aggregates used in this study derived from a drop shatter test on 32 intact soil cores taken from the field and dropped from $2 \mathrm{~m}$ height on a concrete floor in the laboratory (see Munkholm et al., 2012 for further information). The surface area produced for the individual cores (DSA) was correlated to the mean or geometric mean aggregate parameters reported in this study. Across all treatments there was a significant negative correlation between $\mathrm{DS}_{\mathrm{SA}}$ and $\log \mathrm{Y}(\mathrm{r}=-0.65)$ and a significant positive correlation between $\mathrm{DS}_{\mathrm{SA}}$ and aggregate total porosity, $\varepsilon_{\mathrm{T}}^{\text {agg }}(\mathrm{r}=0.68)$ as shown in Figure 5. This means that more than $40 \%$ of the variation in $\mathrm{DS}_{\mathrm{SA}}$ could be explained by either $\log \mathrm{Y}$ or $\varepsilon_{\mathrm{T}}{ }^{\text {agg }}$. When combining these two parameters, DS $\mathrm{SA}_{\mathrm{SA}}$ could be estimated from:

$$
\text { surface area }=0.36-0.97 \log Y+0.06 \varepsilon_{T}^{\text {agg }} \quad \mathrm{R}^{2}=0.55 \quad \text { Eq. } 11
$$

There was no significant correlation to the other aggregate pore or shape characteristics.

\section{Discussion}

\subsection{Treatment effects on soil pore characteristics}

Tillage had strong and significant effect on bulk soil total porosity (i.e. highest for MP) whereas rotation only significantly affected aggregate porosity. This indicates that tillage primarily affected inter-aggregate whereas rotation mainly affected intra-aggregate pore space. Highest BD was found for R1-NT and lowest for R6-MP for both aggregates and cores. The strong effect of tillage on BD for bulk soil was not surprising as many other studies have shown a strong effect of tillage on inter- 
aggregate pore space (e.g. Kadziene et al., 2011). The positive effect of a diverse rotation (R6) on intra-aggregate pore space may be ascribed to higher inputs of organic carbon than in the continuous corn rotation (R1). The R6 rotation has higher average corn yield, and also more active crop growth during the year due to the inclusion of spring cereals and fall growth of red clover cover crop (Meyer-Aurich et al., 2006). A more continuous input of root-associated soil structural binding and bonding components may have stimulated aggregate formation and stabilization. A significant effect of soil management on aggregate porosity has also been found in previous studies (e.g. Munkholm et al., 2002; Blanco-Canqui and Lal, 2007 and Kravenchenko et al., 2011). BlancoCanqui and Lal (2007) showed that aggregate density decreased with input of organic matter after ten years of wheat straw incorporation.

The X-ray micro-CT resolvable porosities were $9.7 \mathrm{~m}^{3} 100 \mathrm{~m}^{-3}$ for images with $40 \mu \mathrm{m}$ voxel size. This is within the same range as reported by Naveed et al. (2014) for 8-16 mm natural aggregates scanned with $30 \mu \mathrm{m}$ resolution but smaller than the c. $14 \mathrm{~m}^{3} 100 \mathrm{~m}^{-3}$ measured for $5 \mathrm{~mm}$ natural aggregates at $9 \mu \mathrm{m}$ resolution by Zhou et al. (2013). In this study there was no significant effect of treatment on X-ray micro-CT resolvable pore characteristics (Table 1). However, there was an insignificant trend to larger $\varepsilon_{\mathrm{T}}{ }^{\mathrm{CT}}$ for MP than for NT which is in correspondence with the results from X-ray micro-CT scanning of soil cores used to generate the aggregates (Munkholm et al., 2013). Others have found significant long-term effect of land use and soil management on CT resolvable pore characteristics (Zhou et al., 2013; Naveed et al., 2014).

There was no treatment effect on the fraction of the CT resolvable pore space isolated within the aggregates, i.e. c. $20 \%$ for all treatments. This is a lower level than reported for natural aggregates by Zhou et al. (2013) (30-55\%) and much lower than shown by Peth et al. (2008) (65-75\%). This is most likely due do difference in soil, scanning resolution and image analysis methodology.

\subsection{Treatment effects on shape and strength characteristics}

In general, the aggregates in this study were more elongated than found by others. The mean aspect ratios were 0.41 for $1_{1} / l_{3}$ and 0.67 for $l_{2} / l_{3}$, which were lower the values of $0.49-0.75$ for $l_{1} / l_{3}$ and 0.67-0.87 for $l_{2} / l_{3}$ reported by Perfect et al. (1997) and references therein. More elongated aggregates in our study may be related to soil type and/or the fact that we measured the lengths automatically based on 3D images as compared to manual measurements in previous studies. 
The aggregates from the diverse rotation, R6, were significantly more round than those from the continuous corn, R1. This may be related to a higher input of organic matter input in R6 and would thus be in agreement with observations by Dexter (1985). Tillage did not affect shape parameters, except $S_{S}$, in this study. This contradicts with Perfect et al. (1997) who reported more elongated aggregates for NT than for MP on a silt loam. However, there is in general paucity of data on soil and management effects on aggregate shape properties.

There was in general a poor correlation between aggregate tensile strength and microstructure characteristics (Table 3; Figure 3 and 4), which was surprising given the well-known role of pore characteristics on aggregate fragmentation. The negative but weak correlation to aggregate porosity was as hypothesized. A much stronger correlation was observed by Naveed et al. (2014) for natural aggregates and regenerated aggregates without organic matter treatment. However, regenerated aggregates with organic matter treatment displayed no significant relationship in their study. It has also to be mentioned that their study was based on much fewer aggregates $(n=27)$ than our study $(n=316)$. An improved fit may have been found if we had been able to combine porosity with pore morphology characteristics such as connectivity and orientation as found by Munkholm et al. (2012) in relation to drop shatter of soil cores. However, the weak correlation between general aggregate pore characteristics and tensile strength is probably due to the fact that fracture of the aggregates is expected to start by an opening of a single crack (Hallett et al., 2013). This indicates a strong dependence on local rather than general aggregate characteristics, which may cause substantial variation in tensile strength. Our study indicates, therefore, that caution has to be taken when trying to predict aggregate tensile strength from general aggregate pore characteristics.

Of the microstructure properties, sphericity showed the strongest correlation $(r=0.27-41$ for individual treatments) to tensile strength (Table 2 and Figure 4). This means, that in general only around $10 \%$ of the variation could be explained by sphericity. It confirms, however, that aggregate shape is an important source of variation in tensile strength as earlier stated by e.g. Dexter and 
The surface area, produced by the drop shatter test, on minimal disturbed cores, could, to a large

361 extent, be explained by the strength and porosity of air-dry aggregates produced by the drop shatter test $\left(\mathrm{R}^{2}=0.55\right)$. This implies that the occurrence of strong and dense aggregates have limited the fragmentation of the soil cores.

\section{Conclusions}

This study confirmed the hypothesized effect of long-term tillage and crop rotation treatments on aggregate shape and pore characteristics, but not on aggregate strength.. The diverse rotation resulted in higher aggregate total porosity and more rounded aggregates than the continuous corn rotation which may be related to higher inputs of organic matter. Surprisingly, there was no treatment effect on X-ray micro-CT resolvable porosities.

371 Aggregate strength decreased as expected with both total and X-ray micro-CT resolvable porosity 372 even though the correlations were weak. Significant correlation was also found to aggregate sphericity although only around $10 \%$ of the variation in tensile strength could be explained by this property. Our study highlights that caution must be taken when trying to predict aggregate strength from general aggregate characteristics.

There was correspondence between bulk soil and aggregate total porosity in the ranking of treatment R6-MP with highest and R1-NT with lowest porosity. Tillage had strongest effect on bulk soil porosity whereas rotation mainly affected aggregate total porosity. Thus, our study suggests that the scale of observation is important when evaluating the influence of soil management. A strong correlation was found between aggregate strength and pore characteristics and soil

381 fragmentation in a drop shatter test, i.e. $55 \%$ of the variation could be explained. Our study 382 indicates therefore that bulk soil fragmentation behavior can be predicted from aggregate characteristics.

384 The conclusions in this study are based on observations from one long-term field experiment on a 385 silt loam soil. More studies are needed to evaluate the long-term effect of management and the 386 relationship between measurements at different scales. 
This work was supported by the OECD Co-operative Research Programme Fellowship, Trade and Agriculture (TAD/PROG) and the Danish ministry for Food, Agriculture and Fisheries through the CoolCrop, OptiPlant and OptiTill projects. The help received from Tatiana Rittl during sampling is gratefully acknowledged.

\section{References}

Ball, B.C., 2013. Soil structure and greenhouse gas emissions: a synthesis of 20 years of experimentation. Eur. J. Soil Sci. 64, 357-373.

Ball, B.C., Batey, T., Munkholm, L.J. 2007. Field assessment of soil structural quality - a revision of the Peerlkamp test, Soil Use Man. 23, 329-337.

Ball, B.C., Batey, T., Munkholm, L.J., Guimarães, R.M.L., Boizard, H., McKenzie, D.C., Peigné, J., Tormena, C.A., Hargreaves, P. 2015.The numeric visual evaluation of subsoil structure (SubVESS) under agricultural production. Soil Till. Res. 148, 85-96.

Blanco-Canqui, H., Lal, R., 2007. Soil structure and organic carbon relationships following 10 years of wheat straw management in no-till. Soil Till. Res. 95, 240-254.

Braunack, M.V., Hewitt, J.S., Dexter, A.R., 1979. Brittle fracture of soil aggregates and the compaction of aggregate beds. J. Soil Sci. 30, 653-667.

Braunack, M.V., Dexter, A.R., 1989. Soil aggregation in the seedbed: a review. I. Properties of aggregates and beds of aggregates. Soil Till. Res.14,259-279.

CSSC, 1998. The Canadian System of Soil Classification, third ed.

Dexter, A.R., Kroesbergen, B., 1985. Methodology for determination of tensile strength of soil aggregates. J. Agric. Eng. Res. 31, 139-147.

Dexter, A.R., 1985. Shapes of aggregates from tilled layers of some Dutch and Australian soils. Geoderma, 35, 91-107. 
Doube, M., Kłosowski, M.M., Arganda-Carreras, I., Cordelières, F, Dougherty, R.P., Jackson, J., Schmid, B., Hutchinson, J.R., Shefelbine, S.J., 2010. BoneJ: free and extensible bone image analysis in ImageJ, Bone, 47, 1076-1079.

Elliot, T.R., Heck, R.J., 2007. A comparison of optical and X-ray CT technique for void analysis in soil thin section. Geoderma, 141, 60-70.

FAO, 1990. Guidelines for soil description. $3^{\text {rd }}$ edition. Soil Resource Management and Conservation Service, Land and Water Division. Food and Agriculture Organzation of the United Nations, Rome. 70 pp.

Garbout, A., Munkholm, L.J., Hansen, S.B. 2013. Temporal dynamics for soil aggregates determined using X-ray CT scanning. Geoderma, 204-205, 15-22.

GE Healthcare, 2006. MicroView 2.1.2 - MicroCT Visualization and Analysis. London, Canada.

Hallett, P.D., Dexter, A.R., Seville, J.P.K., 1995. Identification of pre-existing cracks on soil fracture surfaces using dye. Soil Till. Res. 33, 163-184.

Hallett, P.D., Dexter, A.R., Yoshida, S., 2013. A history of understanding crack propagation and the tensile strength of soil, in: Logsdon, S., Berli, M., Horn, R. (Eds), Quantifying and Modeling Soil Structure Dynamics, Soil Science Society of America, Inc., Madison WI, pp. 93-119.

Håkansson, I., Myrbeck, Å., Etana, A., 2002. A review of research on seedbed preparation for small grains in Sweden. Soil Till Res., 64, 23-40.

Holden, N.M., 1993. A 2-Dimensional Quantification of Soil Ped Shape. J. Soil Sci., 44, 209-219.

Holden,N.M., 1995. Temporal variation in ped shape in an old pasture soil. Catena, 24, 1-11.

Imhoff,S., Pires da Silva,A. Dexter,A.R., 2002. Factors contributing to the tensile strength and friability of oxisols. Soil Sci. Soc. Am. J., 66, 1656-1661.

Kay,B.D., Angers,D.A., 2001. Soil structure. In: Sumner, M.E. (Ed.), Handbook of Soil Science. CRC Press, Boca Raton, pp. 229-276.

Kadziene, G., Munkholm, L.J., Mutegi, J.K., 2011. Root growth conditions in the topsoil as affected by tillage intensity. Geoderma, 166, 66-73. 
Kay, B.D., Dexter, A.R. 1990. Influence of aggregate diameter, surface area and antecedent water content on the dispersibility of clay. Can. J. Soil Sci. 70, 665-671.

Kravchenko, A.N., Wang, A.N.W., Smucker, A.J.M., Rivers, M.L., 2011. Long-term Differences in Tillage and Land Use Affect Intra-aggregate Pore Heterogeneity. Soil Sci. Soc. Am. J., 75, 1658-1666.

Krumbein, W.C., Sloss, L.L.,1963. Stratigraphy and Sedimentation, second ed. W.H. Freeman \& Co, San Francisco.

Le Bissonnais, Y., 1996. Aggregate stability and assesment of soil crustability and erodibility: Theory and methodology. Eur. J. Soil Sci., 47, 425-437.

Meteorological Services Canada. 2010. Canadian climate normals: 1971-2000.Available at www.climate.weatheroffice.ec.gc.ca/climate_normals (accessed Dec. 2010). Environment Canada, Ottawa, ON.

Meyer-Aurich, A., Janovicek, K, Deen, W, Weersink, A., 2006. Impact of tillage and rotation on yield and economic performance in corn-based cropping systems. Agron. J., 98, 1204-1212.

Munkholm, L.J., 2011. Soil friability: A review of the concept, assessment and effects of soil properties and management Geoderma 167-168, 236-246.

Munkholm, L.J., Kay, B.D., 2002. Effect of water regime on aggregate-tensile strength, rupture energy, and friability. Soil Sci. Soc. Am. J. 66, 702-709.

Munkholm, L.J., Schjønning, P., Kay, B.D., 2002. Tensile strength of soil cores in relations to aggregate strength, soil fragmentation and pore characteristics. Soil Till. Res., 64, 125-135.

Munkholm, L.J., Heck, R., Deen, B., 2013. Long-term effects of rotation and tillage on visual evaluation of soil structure, soil physical properties and crop yield. Soil Till. Res., 127, 85-91.

Munkholm, L.J., Heck, R.J., Deen, B., 2012. Soil pore characteristics assessed from X-ray microCT derived images and correlations to soil friability. Geoderma 181-182, 22-29.

Naveed, M., Arthur, E., de Jonge, L.W., Tuller, M., Moldrup, P., 2014. Pore structure of natural and regenerated soil aggregates: An x-ray computed tomography analysis. Soil Sci. Soc. Am. J. 78, 377-386. 
466 Perfect, E., Zhai, Q., Blevins, R.L., 1997. Soil and tillage effects on the characteristic size and shape of aggregates. Soil Sci. Soc. Am. J., 61, 1459-1465.

Peth, S., Horn, R., Beckmann, F., Donath, T., Fischer, J., Smucker, A.J.M., 2008. ThreeDimensional Quantification of Intra-Aggregate Pore-Space Features using SynchrotronRadiation-Based Microtomography. Soil Sci. Soc. Am. J. 72, 897-907.

Rasband, W., 2005. ImageJ. National Institute of Health, Bethesda MD.

SAS Institute, 2005. SAS Institute, SAS/STAT ${ }^{\text {TM }}$ Software: Language reference and concepts Release 9.1.3, SAS Institute, Cary, NC.

Sneed, E.D., Folk, R.L., 1958. Pebbles in the Lower Colorado River, Texas a Study in Particle Morphogenesis. J. Geol., 66, 114-150.

Watts, C.W., Dexter, A.R., 1998. Soil friability: theory, measurement and the effects of management and organic carbon content. Eur. J. Soil Sci., 49, 73-84.

WRB, 2006. World reference base for soil resources 2006. Food and Agriculture Organization of United Nations, Rome.

Young, I.M., Crawford, J.W., Rappoldt, C., 2001. New methods and models for characterising structural heterogeneity of soil. Soil Till. Res. 61, 33-45.

Zhou,H., Peng,X., Perfect,E., Xiao,T., Peng,G., 2013. Effects of organic and inorganic fertilization on soil aggregation in an Ultisol as characterized by synchrotron based X-ray micro-computed tomography. Geoderma, 195, 23-30. 
Table 1. Treatment effects on soil pore characteristics. $\mathrm{BD}_{\text {core }}$ and $\mathrm{BD}_{\mathrm{agg}}$ are dry bulk density values for soil cores and aggregates, respectively. The parameters $\varepsilon_{\mathrm{T}}, \varepsilon_{\mathrm{T}}{ }^{\mathrm{CT}}, \varepsilon_{\mathrm{s}}$ and $\varepsilon_{\mathrm{i}}$ are total porosity for the aggregates, X-ray CT resolvable porosity, surface connected Xray $\mathrm{CT}$ resolvable porosity and isolated X-ray CT resolvable porosity. Figures with different letters within treatments are significant at $\mathrm{P}<0.05$ level

\begin{tabular}{lccccccc}
\hline Treatment & $\mathrm{BD}_{\text {core }}{ }^{*}$ & $\mathrm{BD}_{\mathrm{agg}}$ & $\varepsilon_{\mathrm{T}}{ }^{\mathrm{core}}{ }^{*}$ & $\varepsilon_{\mathrm{T}}{ }^{\mathrm{agg}}$ & $\varepsilon_{\mathrm{T}}{ }^{\mathrm{CT}}$ & $\varepsilon_{\mathrm{S}}{ }^{\mathrm{CT}}$ & $\varepsilon_{\mathrm{I}}{ }^{\mathrm{CT}}$ \\
\hline R1-NT & $1.48^{\mathrm{a}}$ & 1.70 & 44.2 & 36.0 & 9.5 & 7.6 & 1.8 \\
R1-MP & $1.31^{\mathrm{b}}$ & 1.68 & 50.6 & 36.7 & 10.4 & 8.5 & 1.9 \\
R6-NT & $1.43^{\mathrm{a}}$ & 1.67 & 46.0 & 36.9 & 9.1 & 7.4 & 1.8 \\
R6-MP & $1.25^{\mathrm{b}}$ & 1.62 & 52.8 & 38.4 & 9.7 & 7.9 & 1.7 \\
\hline Averages across rotation & & & & & & \\
\hline R1 & 1.40 & 1.69 & 47.2 & 36.3 & $100 \mathrm{~m}^{-3}$ \\
R6 & 1.34 & 1.65 & 49.4 & 37.6 & 9.4 & 7.6 & 1.8 \\
\hline Averages across tillage & & & & & & 1.8 \\
\hline NT & $1.46^{\mathrm{a}}$ & 1.68 & $44.9^{\mathrm{a}}$ & 36.5 & 9.3 & 7.5 & 1.8 \\
MP & $1.28^{\mathrm{b}}$ & 1.66 & $51.7^{\mathrm{b}}$ & 37.5 & 10.0 & 8.2 & 1.8 \\
\hline
\end{tabular}

${ }^{*}$ From Munkholm et al. 2013. 
Table 2. Treatment effects on shape and strength characteristics. The parameters $1_{1}$, $1_{2}, l_{3}$ are geometric mean values for the minor, intermediate and major length of the aggregates. $L_{\mathrm{c}}$ is the equivalent cubic length, $1_{1} / \mathrm{l}_{3}$ and $\mathrm{l}_{2} / \mathrm{l}_{3}$ are aspect ratios, $\mathrm{S}_{\mathrm{s}}$ and $\mathrm{S}_{\mathrm{e}}$ are sphericity estimates for spheres and ellipsoids, respectively, $\mathrm{Y}$ is the tensile strength geometric mean values and FI is friability index. Figures with different letters within treatments are significant at $\mathrm{P}<0.05$ level..

\begin{tabular}{lllllllllll}
\hline Treatment & $\mathrm{l}_{1}$ & $\mathrm{l}_{2}$ & $\mathrm{l}_{3}$ & $\mathrm{~L}_{\mathrm{c}}$ & $\mathrm{l}_{1} / \mathrm{l}_{3}$ & $\mathrm{l}_{2} / \mathrm{l}_{3}$ & $\mathrm{~S}_{\mathrm{S}}$ & $\mathrm{S}_{\mathrm{E}}$ & $\mathrm{Y}$ & $\mathrm{FI}$ \\
\hline & $\mathrm{mm}$ & $\mathrm{mm}$ & $\mathrm{mm}$ & $\mathrm{mm}$ & & & & & $\mathrm{kPa}$ & \\
\hline R1-NT & 4.4 & 7.4 & 11.9 & 5.5 & 0.38 & 0.63 & 0.51 & 0.60 & 84 & 0.45 \\
R1-MP & 4.5 & 8.0 & 12.3 & 5.8 & 0.40 & 0.67 & 0.48 & 0.61 & 89 & 0.36 \\
R6-NT & 4.5 & 7.5 & 10.9 & 5.5 & 0.42 & 0.68 & 0.52 & 0.63 & 88 & 0.47 \\
R6-MP & 4.7 & 7.5 & 11.4 & 5.4 & 0.44 & 0.71 & 0.49 & 0.65 & 63 & 0.43 \\
\hline Averages across rotation & & & & & & & & \\
\hline R1 & 4.5 & 7.7 & 12.1 & 5.6 & $0.39^{\mathrm{b}}$ & 0.65 & 0.49 & 0.61 & 86 & 0.41 \\
R6 & 4.6 & 7.5 & 11.1 & 5.4 & $0.43^{\mathrm{a}}$ & 0.69 & 0.51 & 0.64 & 75 & 0.45 \\
\hline Averages across tillage & & & & & & & & \\
\hline NT & 4.4 & 7.4 & 11.6 & 5.5 & 0.40 & 0.66 & 0.51 & 0.62 & 86 & 0.46 \\
MP & 4.6 & 7.8 & 11.5 & 5.6 & 0.42 & 0.69 & 0.49 & 0.63 & 75 & 0.40 \\
\hline
\end{tabular}


Table 3. Pearson correlations between tensile strength (log values) and porosity and shape parameters. The bold values are significant at the $\mathrm{P}<0.05$ level.

\begin{tabular}{|c|c|c|c|c|c|}
\hline & R1 & & R6 & & All \\
\hline & MP & NT & MP & NT & \\
\hline & $\mathrm{n}=79$ & $\mathrm{n}=78$ & $\mathrm{n}=80$ & $\mathrm{n}=79$ & $\mathrm{n}=316^{*}$ \\
\hline$\varepsilon_{\mathrm{T}^{\mathrm{agg}}}^{\mathrm{agg}}$ & -0.13 & -0.20 & -0.10 & -0.16 & -0.18 \\
\hline$\varepsilon_{\mathrm{T}}{ }^{\mathrm{CT}}$ & -0.05 & -0.41 & -0.12 & -0.03 & -0.12 \\
\hline$\varepsilon_{S}{ }^{C T}$ & -0.08 & -0.42 & -0.16 & -0.06 & -0.16 \\
\hline$\varepsilon_{\mathrm{I}}^{\mathrm{CT}}$ & 0.11 & -0.22 & -0.05 & 0.11 & 0.04 \\
\hline $\log 1_{1}$ & 0.05 & -0.11 & 0.06 & -0.09 & 0.01 \\
\hline $\log l_{2}$ & -0.22 & -0.21 & -0.02 & -0.07 & -0.12 \\
\hline $\log 1_{3}$ & -0.27 & -0.35 & -0.06 & -0.08 & -0.15 \\
\hline $\log L_{c}$ & -0.22 & -0.21 & -0.01 & -0.11 & -0.12 \\
\hline $1_{1} / 1_{3}$ & 0.08 & 0.19 & 0.05 & 0.07 & 0.06 \\
\hline $1_{2} / 1_{3}$ & 0.26 & 0.37 & 0.08 & 0.06 & 0.14 \\
\hline $\mathrm{S}_{\mathrm{S}}$ & 0.41 & 0.27 & 0.29 & 0.30 & 0.31 \\
\hline $\mathrm{S}_{\mathrm{E}}$ & 0.26 & 0.35 & 0.09 & 0.02 & 0.14 \\
\hline
\end{tabular}

*Results from four aggregates were excluded from the analysis as these were considered outliers. 


\section{Figure Captions}

Figure 1. Photo showing the placement of aggregates from sample \#11and \#12 in the cylinder used for X-ray micro-CT scanning. The aggregates were from treatment mouldboard ploughing (MP), diverse rotation $(\mathrm{R} 6)$.

Figure 2. An example (\#11B compartment -samples 6-10) showing an image from X-ray micro-CT scanning at $40 \mu \mathrm{m}$ resolution. The aggregates were from treatment mouldboard ploughing (MP), diverse rotation (R6). A: X-ray micro-CT scanning image. B: Binary X-ray micro-CT scanning “filled holes" image.

Figure 3. Correlation between aggregate tensile strength $(\log \mathrm{Y})$ and aggregate pore characteristics: total porosity, $\varepsilon_{\mathrm{T}}{ }^{\text {agg }}$, total X-ray CT resolvable porosity, $\varepsilon_{\mathrm{T}}{ }^{\mathrm{CT}}$ and X-ray CT resolvable surface connected porosity, $\varepsilon_{S}{ }^{\mathrm{CT}}$.

Figure 4. Correlation between aggregate tensile strength $(\log \mathrm{Y})$ and aggregate shape characteristics: log major length $\left(l_{3}\right)$, aspect ratio $l_{2} / l_{3}$ and sphericity $S_{s}$.

Figure 5. Correlation between surface area $\left(\mathrm{DS}_{\mathrm{SA}}\right)$ produced in a drop shatter test and the aggregate characteristics: total porosity, $\varepsilon_{\mathrm{T}}{ }^{\mathrm{agg}}$ and tensile strength (log $\left.\mathrm{Y}\right)$. 
Figure 1. Photo showing the placement of aggregates from sample \#11 and \#12 in the cylinder used for X-ray micro-CT scanning. The aggregates were from treatment mouldboard ploughing (MP), diverse rotation (R6).

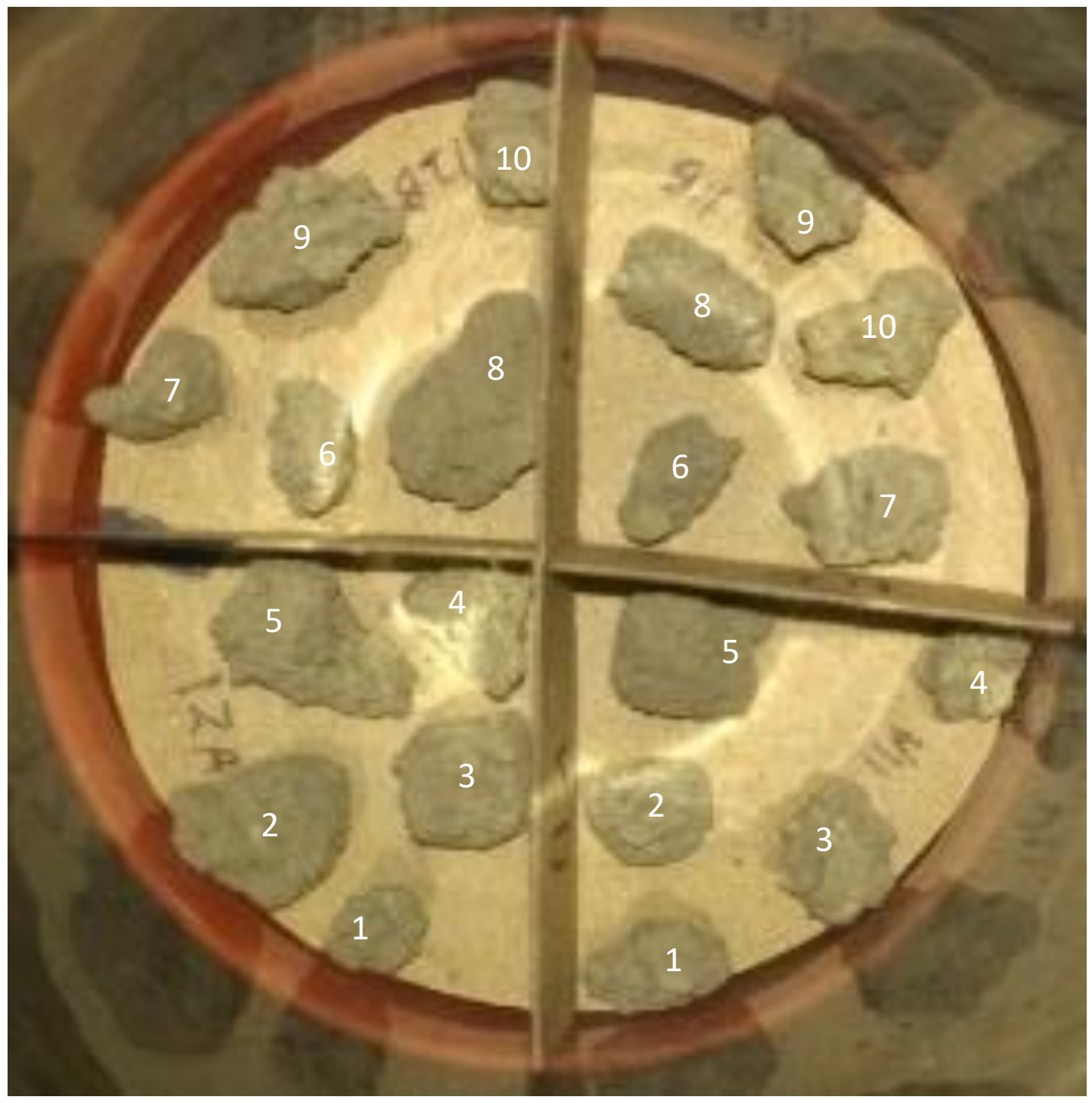


Figure 2. An example (\#11B compartment -samples 6-10) showing an image from X-ray microCT scanning at $40 \mu \mathrm{m}$ resolution. The aggregates were from treatment moldboard ploughing (MP), diverse rotation (R6). A: X-ray micro-CT scanning image. B: Binary X-ray micro-CT scanning "filled holes" image. Examples of a isolated and surface connected pore at 2D scale is illustrated.
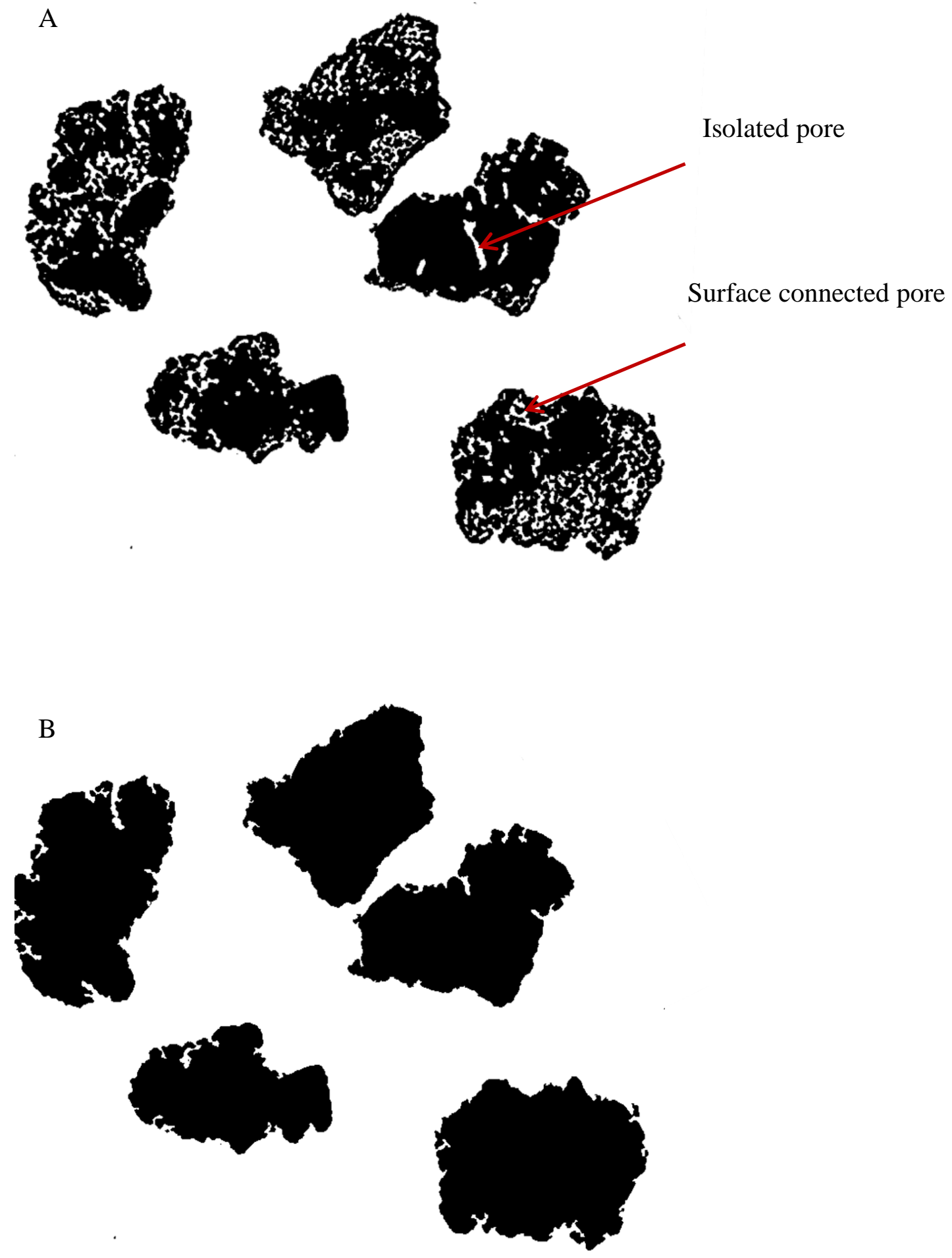

26 
Figure 3. Correlation between log aggregate tensile strength, (Y, $\mathrm{kPa})$ and aggregate pore characteristics: total porosity, $\varepsilon_{\mathrm{T}}{ }^{\mathrm{agg}}$, total X-ray CT resolvable porosity, $\varepsilon_{\mathrm{T}}{ }^{\mathrm{CT}}$ and X-ray CT resolvable surface connected porosity, $\varepsilon_{\mathrm{S}}{ }^{\mathrm{CT}}$.

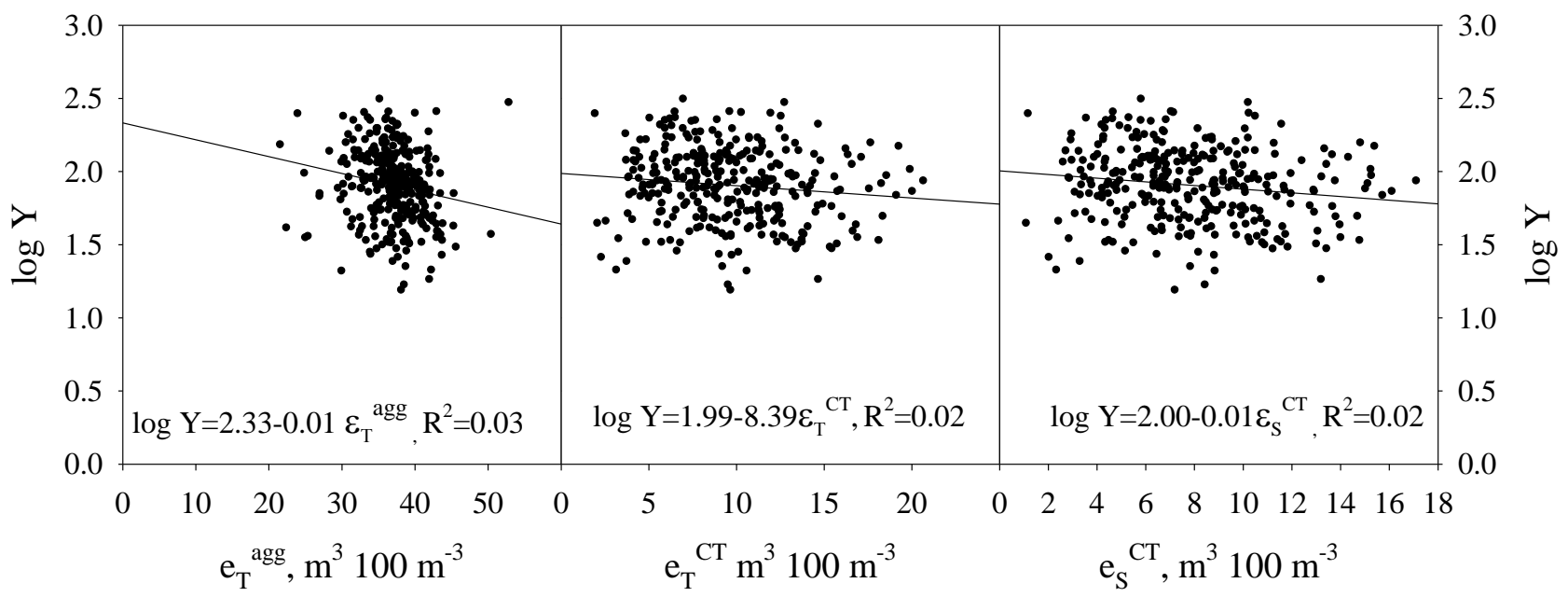


Figure 4. Correlation between log aggregate tensile strength (Y, $\mathrm{kPa})$ and aggregate shape characteristics: $\log$ major length $\left(l_{3}\right)$, aspect ratio $l_{2} / l_{3}$ and sphericity $S_{S}$.

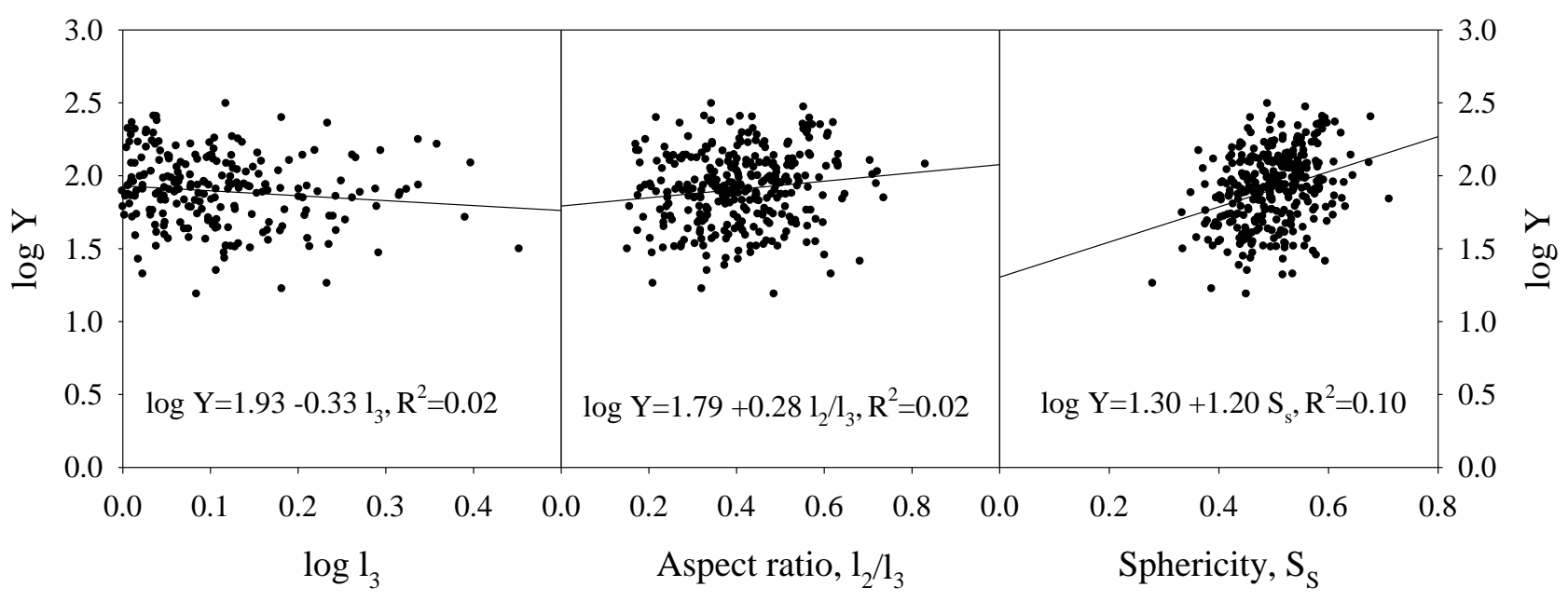


Figure 5. Correlation between surface area $\left(\mathrm{DS}_{\mathrm{SA}}\right)$ produced in a drop shatter test and the aggregate characteristics: total porosity, $\varepsilon_{\mathrm{T}}{ }^{\mathrm{agg}}$ and log tensile strength $\mathrm{Y}(\mathrm{kPa})$.

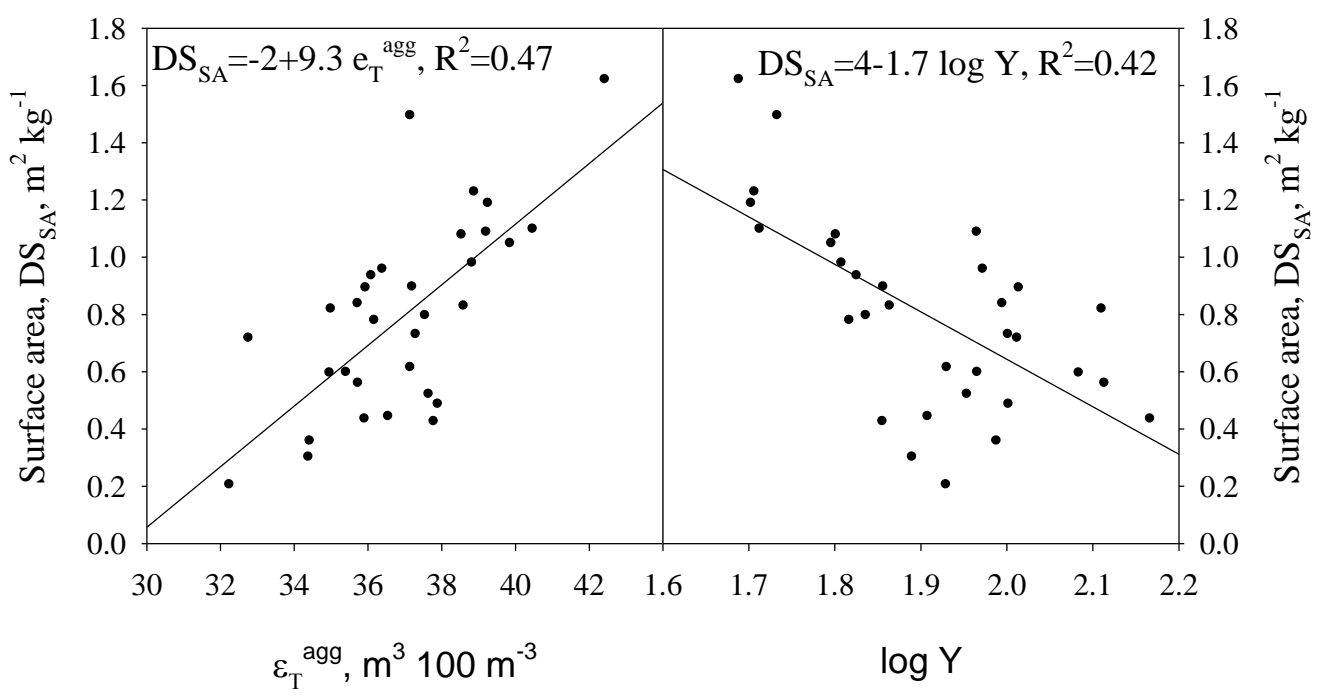

